\title{
The Relationships between Personal Values, Justifications, and Academic Cheating for Business vs. Non-Business Students
}

\author{
Laura Parks-Leduc ${ }^{1}$ (D) Russell P. Guay ${ }^{2}$ (D) - Leigh M. Mulligan ${ }^{3}$
}

Accepted: 9 June 2021 / Published online: 22 June 2021

(c) The Author(s), under exclusive licence to Springer Nature B.V. 2021

\begin{abstract}
In this study we examine college cheating behaviors of business students compared to nonbusiness students, and investigate possible antecedents to cheating in an effort to better understand why and when students cheat. We specifically examine power values; we found that they were positively related to academic cheating in our sample, and that choice of major (business or non-business) partially mediated the relationship between power values and cheating. We also considered the extent to which students provide justifications for their cheating, and found that business students were more likely to justify (rationalize) their cheating behaviors. Finally, we update the literature in terms of the ways students cheat. We assess newer forms of academic cheating, as increased accessibility to information via the Internet and smartphones may have changed the ways and ease with which students cheat - a particularly relevant topic currently, as many classes have moved online during the COVID-19 pandemic. In our study, cheating was especially prevalent when taking quizzes or tests or completing homework online. We found that only $10 \%$ of participants reported never engaging in any of the cheating behaviors we examined.
\end{abstract}

Keywords Business Students · Cheating · Values · Un-prescribed Adderall

Laura Parks-Leduc

leduclm@jmu.edu

Russell P. Guay

russell.guay@uni.edu

Leigh M. Mulligan

mulliglm@gmail.com

1 James Madison University, 421 Bluestone Dr.; Hartman Hall 1011, Harrisonburg, VA 22807, USA

2 University of Northern Iowa, Cedar Falls, IA, USA

3 Philadelphia, PA, USA 


\section{Introduction}

Colleges succeed in their missions when students master the material that is presented to them. Students who cheat without getting caught receive credit for learning outcomes that they have not actually mastered, circumventing the goal of the academic institution. This problem is substantial; a majority of college students have reported cheating at least once during their time in college (Jensen et al., 2002). The cheating rate has been a problem at least since the 1940s, when it was reported at 23\% (Drake, 1941), with more recent rates of 74\% (Jendrek, 1992; West et al., 2004) and even as high as 90\% (Graham, 1994). Cheating in college is a critical concern, a point that is illustrated by the fact that the Chronicle of Higher Education recently published a case study on building academic integrity (Chronicle of Higher Education, 2018).

While cheating in college is clearly problematic, evidence suggests this is more prevalent in business schools. Multiple studies have examined the differences in cheating between business and non-business students. Bowers (1967) found in a multi-university study that $66 \%$ of business students reported cheating, and comprised the largest academic group to report cheating. McCabe and Trevino (1995) later found similarly that $84 \%$ of surveyed business students reported cheating, while the average rate of cheating was 66\% among all undergraduate students. Similar studies (see Mangan, 2006; McCabe et al., 1993) showed that MBA students were also more prone to academic cheating relative to other types of graduate students.

It is clear from these prior studies that cheating is an ongoing issue on college campuses, particularly within business schools. This study examines the current frequency of cheating among business and non-business students. In an effort to better understand why students cheat, and why business students cheat more than non-business students, we also explore some of the possible antecedents to cheating, including personal values and justifications (rationalizations) of cheating behavior. We additionally examine how cheating behaviors have changed as advances in technology and society have made cheating easier. In particular, the increased availability of resources on the Internet, such as online term paper "mills" (Campbell et al., 2000) means that students have more mechanisms for cheating than in the past. Additionally, while in-person test environments represent a strong situation in which there are clear expectations for behavior, online assessments likely represent a weaker situation with greater ambiguity, in which it may be easier to rationalize cheating behavior (Lee et al., 2019).

\section{Unethicality and Academic Cheating Among Business Students}

Corporate scandals seem to be persistent in the business world, and each new scandal renews public interest in understanding why people behave unethically in business settings. There is a growing perception that business schools share at least part of the blame. Business schools are often blamed for cultivating unethical behaviors in their students, who then enact this unethical behavior in the business world (Dean \& Beggs, 2006). Some researchers (e.g., Huhn, 2014; Miller, 1999) propose that the theories and ideas from business courses teach self-interested mentalities that can affect students' ethical decision making. They propose that students have learned to be less ethical as a result of their business coursework. 
While evidence supports the contention that business students cheat more than nonbusiness students (e.g., Bowers, 1967; McCabe \& Trevino, 1995), some researchers have argued that the unethical behaviors of business students relate to their inherent character and that students who choose to study business have different values from those who choose other majors (Frank \& Schultz, 2000). This approach proposes that business students engage in more unethical behavior - including academic cheating - because of underlying individual differences, rather than as a result of what they learn in classes.

\section{Personal Values}

We examine personal values in this study, as one proposed explanation for why business students cheat more is that their values may differ from those of non-business students. Frank and Schultz (2000) found that economics ${ }^{1}$ students were more corruptible in a social dilemma experiment, but that those differences were detectable as soon as students selected economics as a major, prior to having a single economics course. This supports the premise that business students may self-select their major based on individual characteristics also associated with ethical or unethical behavior. We therefore examine values as a possible predictor of both choice of major and of cheating behaviors.

Personal values are cognitive representations of important motivations and goals (Bilsky $\&$ Schwartz, 1994) that are relatively stable and serve as guiding principles regarding how people - both self and others - ought to behave (Parks \& Guay, 2009; Schwartz, 1992). The dominant taxonomy for studying personal values is the Schwartz Value Theory, which groups values into 10 domains based on the motivations underlying them. The 10 domains are Power, Achievement, Hedonism, Stimulation, Self-Direction, Universalism, Benevolence, Conformity, Tradition, and Security. The Schwartz Value Theory and structure has been examined in more than 75 countries with considerable consistency (Schwartz, 2011), and seems quite robust for describing and organizing personal values.

Personal values have been shown to be strong predictors of attitudes, decision-making, motivation, and behavior (Parks \& Guay, 2012; Rokeach, 1973; Schwartz, 1992, 2011), and create a standard against which to judge and evaluate the behavior of oneself and of others (Parks \& Guay, 2009; Rokeach, 1973). A failure to act in accordance with one's values typically causes cognitive dissonance (Rokeach, 1973), while acting consistently with one's values enables individuals to feel good about themselves (Sheldon \& Elliott, 1999). As such, values can exert a strong influence on motivated behavior. Research suggests that value-consistent behavior is not automatic; acting consistently with one's values typically involves a cognitive evaluation of what behavior will help the individual fulfill stronglyheld values in a given situation (Parks-Leduc et al., 2015). Cheating would seem to be both a motivated behavior and one that an individual decides to engage in after a cognitive evaluation of the situation. We therefore anticipate that values will be relevant to cheating. In particular, we expect power values to be relevant to academic cheating.

Power values are quite self-serving; they are defined as beliefs that one should be in charge and have control over resources, be viewed as important, have prestige and social

\footnotetext{
1 While we realize that Economics students are not always considered to be business students, the institution used in this paper, like many other universities, does have their Economics major as part of their business school.
} 
status, and have authority over others (Bye et al., 2011; Parks \& Guay, 2009; Schwartz, 1992). Viewing oneself as more important than others implies a lack of concern for others, which suggests that power values may be relevant in predicting unethical cheating behavior. Research supports this notion, as a study of students completing managerial "in-basket" decision-making activities demonstrated that power values were associated with making decisions more destructive to the organization and its members (Ilies \& Reiter-Palmon, 2008). Power values have also been shown to relate negatively to level of moral development (Lan et al., 2008) and moral competence (Pohling et al., 2015). A meta-analysis (Feldman et al., 2015) also concluded that power values were predictive of unethicality. Though not previously examined in the context of academic cheating, the above studies suggest that power values will likely be relevant in this setting.

One could argue that achievement values should also be related to academic cheating. Achievement values relate to beliefs that one should have socially recognized successes (Schwartz, 1992). Individuals with strong achievement values want to be successful in sports, in school, and in their careers; however, this does not seem to translate consistently into a desire to cheat to get ahead. Research generally finds pretty weak relationships between achievement values and unethicality (Feldman et al., 2015). This may be because some individuals with strong achievement values may feel that the achievement is only worthwhile if they follow the rules and really earn the recognition, or it could be that their desire for positive recognition also means they fear negative recognition if they are caught.

\section{Justification of Cheating}

While past research has often found that business students cheat more than other students, we do not have a complete understanding as to why. There is evidence that material learned from business courses increases students' selfishness (Krishnan, 2008) and greediness (Wang et al., 2011). Further, Giacalone and Wargo (2009) and Huhn (2014) have argued that both the ideology and pedagogy of business schools increases unethical behavior. A possibility is that business students who cheat may not consider as many behaviors to be unethical relative to non-business students. In support of this premise, Hawkins and Cocanougher (1972) found that business students were more tolerant of questionable practices than non-business students. Miller (1999) proposed that this occurs because business students learn theories of financial rational behavior and other analytical skills focused on profit and success. Many economic theories are predicated on the assumption that individuals behave in a rational, self-interested manner in order to maximize their outcomes and that people use cost-benefit analysis to determine whether benefits outweigh costs. By learning these theories, students may come to believe that they are supposed to behave this way, considering only themselves without taking into account other people, thus potentially leading to unethical behavior (Miller, 1999).

Behavioral economics research seems to support this premise. Ariely (2009) reviews a series of studies in which selling something at a low price increases selfish behavior relative to giving the product away for free. The introduction of the price causes people to shift from social behavior's concern for outcomes of others to financially rational behavior's concern with selfishly maximizing outcomes for oneself. The selfish behavior is justifiable based on the norm of financially rational behavior, but not justifiable under social norms. While purchasing products is quite different from academic cheating, it does seem that being taught that one ought to behave in a financially rational manner could provide students with a justification for selfish behavior - thereby increasing the extent to which 
they are able to engage in rationalization to make their behavior seem more acceptable. We were therefore interested in exploring whether business students find it easier to justify their cheating behaviors relative to non-business students, as this would also help to explain why business students cheat more.

Cognitive and ethical dissonance theories (Barkan et al., 2015; Festinger, 1957) propose that individuals experience discomfort when their attitudes, beliefs, and/or behaviors are inconsistent with one another. This experience of dissonance motivates change to eliminate the discomfort. This suggests that in order for people to cheat, they must either think of themselves as cheaters or must not consider the behavior to be cheating. Research suggests that the second option is the more common - that people justify their behavior by rationalizing it as something other than cheating; for example, staying competitive by doing what everyone else does (Barkan, 2015). Rationalization is a psychological process through which controversial or inappropriate behaviors, thoughts, or feelings are justified using rational or logical motives (Gert, 2014). The rationalizing or justifying of behavior can be used to avoid negative emotions, such as guilt or shame, and may also be used to protect an individual's self-concept (Pedersen, 2018). Shalvi and colleagues (Shalvi et al., 2012) found that cheating can be diminished by making potential justifications for cheating unavailable.

The theory of self-concept maintenance (Mazar et al., 2008), suggests that people will be more likely to behave unethically when they can do so without harming their self-concept and beliefs that they are inherently honest. The theory also proposes that one of the two ways that people do this is by categorizing/justifying/rationalizing their behaviors as something other than dishonest behavior. This suggests that blatant forms of cheating will be less prevalent, because they are harder to justify, while minor forms of cheating will be more common. This premise that has been supported across multiple studies (Ariely, 2013). The theory therefore suggests that dishonest behavior is most likely to occur when it is easy to categorize the behavior as something other than dishonest behavior. While the theory has not, to the best of our knowledge, been tested in academia, researchers (Barkan et al., 2015) have found support for categorization (justification) as a predictor of unethical behavior. In the context of academic cheating, the availability of information via the Internet and the ability to connect with information and resources from one's phone may make justification easier than in the past, suggesting that both justification and cheating are likely prevalent among college students today. We were therefore interested in examining the extent to which students are able to recategorize their cheating behaviors as not cheating.

Hypotheses Previous studies (Bowers, 1967; McCabe \& Trevino, 1995) found that the percentage of business students who cheated was significantly greater than the percentage of all undergraduate students who cheated. In addition, Klein et al. (2007) found that business students' attitudes regarding what constitutes cheating were more lax than those of non-business students, while Owusu et al. (2019) showed that students who desire to get rich are more likely to give into temptation and engage in unethical behavior. Academic cheating can often be a result of desiring high grades that will lead to a prestigious job; business students often place a high importance on both power and success (Feldman et al., 2015). Consistent with these prior studies, we expect students majoring in business to cheat more than non-business majors.

Hypothesis 1: Business students will engage in more academic cheating than nonbusiness students. 
As stated, we do not have a complete understanding of why students cheat, or why business students cheat more often than other students, however, a proposed mechanism is that of justification (McCabe et al., 1993; Stone et al., 2009; Wenzel \& Reinhard, 2020). Justification should enable students to cheat without experiencing dissonance - they justify their behavior by reframing it as something other than cheating. As such, students who justify should also cheat with greater frequency. For example, Gino and Ariely (2012) found that people who are more creative cheat more often as it is easier for them to justify their behavior. Whitley (1998) investigated many factors associated with cheating in college students and found a strong relationship between attitudes towards cheating, specifically justification that the behavior was acceptable, and actual cheating.

Hypothesis 2: Justification will be positively related to academic cheating.

We additionally expect that power values will be positively related to cheating behavior. Individuals who value power tend to place their own wants ahead of the concerns of others, suggesting that they may be more willing to cheat in order to get ahead. Previous research clearly shows that power values are associated with less ethical decision making (Feldman et al., 2015; Ilies \& Reiter-Palmon, 2008), lower levels of moral development (Lan et al., 2008), and less moral competence (Pohling et al., 2015). While prior research has demonstrated a link between power values and unethicality, we extend these previous findings by examining power values as a predictor of academic cheating.

Hypothesis 3: Power values will be positively related to academic cheating.

We also examine whether power values are related to the other predictors in our study - choice of major (business or non-business) and justification. While some theorists have suggested that business schools are to blame for the unethical behavior of business students (Huhn, 2014; Miller, 1999), others have proposed that college does not change business students' ethicality, but that students self-select their business major based on underlying characteristics that make them more likely to behave unethically (Frank \& Schultz, 2000). Perhaps both are correct; students may choose to major in business because of their values, and may additionally develop more lax views about ethics via their coursework and peer group. We therefore also examine the values of business students to see whether they differ from those of non-business students and whether those differences are related to differences in cheating behavior.

We propose that individuals who place greater importance on power values will also be more likely to major in business. We expect that students choose their majors in part because the major is consistent with their values. Past research clearly demonstrates a link between values and decision-making, particularly when that decisionmaking reflects an active, conscious choice (Rokeach, 1973). The choice of a major is one that typically is made after considerable reflection, suggesting that individuals will fully consider whether their major will lead to a career that fulfills their values. We further expect that students with strongly-held power values will be more likely to pursue careers that better allow for that value domain to be expressed. This would be consistent with a career in business. Research also supports this premise; Sagiv and Schwartz (2000) compared the values of business and psychology students, and found that among those two groups, business students scored higher on power values. Similarly, Arieli and colleagues (Arieli et al., 2016) found that business students scored higher on achievement and power values than did social work students. While we include other majors in our study beyond just psychology and social work, we similarly anticipate that business majors will score higher on power values than non-business 
$\mathrm{H} 1$

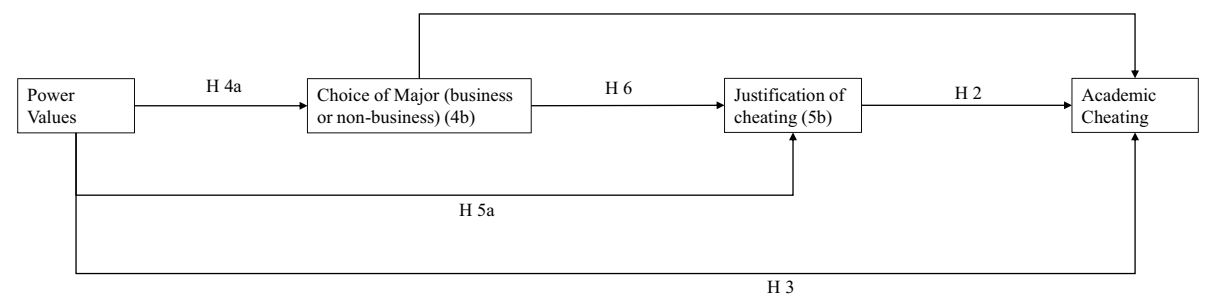

Fig. 1 Proposed Model

majors. Further, if power values cause students to choose business majors, and business students are more likely to cheat because of their values, then choice of major (business vs. non-business) should also mediate the relationship between power values and cheating.

Hypothesis 4a: Business students will have higher average scores for power values relative to non-business students.

Hypothesis 4b: The relationship between power values and academic cheating will be mediated by choice of major (business or non-business).

The theory of self-concept maintenance provides another mechanism to explain how higher power values may lead to more cheating: individuals who value their own success over that of others may be more likely to rationalize their behavior as acceptable to get ahead (Mazar et al., 2008). This suggests that power values may also be related to justification, and that justification will also mediate the relationship between power values and cheating.

Hypothesis 5a: Power values will be positively related to justification.

Hypothesis 5b: The relationship between power values and academic cheating will be mediated by justification.

Finally, we were interested in addressing the question of whether business students cheat more as a consequence of self-selection, the education they receive in business school, or both. If business students cheat more as a result of their business education (Huhn, 2014; Miller, 1999), then they should also engage in more justification to rationalize their behavior. This suggests that justification will mediate the relationship between choice of major and cheating. Alternatively, if business students primarily cheat more because of self-selection into business due in part to their power values, and power values also cause cheating (Frank \& Schultz, 2000), then justification would not mediate the relationship between choice of major and cheating. We expect that both are true - that students self-select into business because of their power values, and that business courses teach principles of self-interest that cause students to justify their behavior more, both of which lead to more cheating. We therefore expect that justification will mediate the relationship between choice of major and cheating. Our complete model is provided in Fig. 1.

Hypothesis 6: The relationship between choice of major (business or non-business) and academic cheating will be mediated by justification. 


\section{Methods}

Participants were undergraduates from a mid-sized, public university in the mid-Atlantic region of the USA. Potential participants were recruited for the study during a class presentation, informed of the volunteer nature of the study, and then sent the anonymous survey link. Professors were not permitted to provide any incentives for taking the survey because this could infringe on the confidentiality of participants. A total of 337 students completed the survey, which represented approximately $13-14 \%$ of those recruited. Six surveys were eliminated due to missing data, leaving a sample size of 331. This sample size is adequate to detect a relatively small change in R-squared using multiple regression (0.039) according to sensitivity analysis using $G^{*}$ Power (Faul et al., 2009). The dataset generated by this study is available in the Mendeley data repository.

Participants reported their major in the survey and were matched to their corresponding college based on their major. Two students had undeclared majors. Fifty-six percent $(n=185)$ of participants were business students. Because our interest was in comparing business to non-business students, we intentionally invited more business students to participate. Approximately $44 \%$ of participants in the study's sample were male (42\% of students at this institution were male). The sample consisted of $3 \%$ freshmen, $8 \%$ sophomores, $55 \%$ juniors, $30 \%$ seniors, and 5\% fifth year students. Data collection was intentionally skewed toward upper-level courses as students would likely have chosen their final major by that point.

\section{Measures}

Cheating frequency. While prior studies have examined cheating behaviors, we wanted to generate a list that would also incorporate newer ways that students cheat given changes in technology. In order to generate a more comprehensive list of current cheating behaviors, a focus group was held with eight students to brainstorm the different ways students cheat. From this focus group, a list of 24 questions was compiled (Table 1). These questions overlap substantially with the academic dishonesty questions asked by McCabe and Trevino (1995), though our list of questions was somewhat more detailed and included some newer methods of cheating. For example, questions included using a cellphone during an exam; completing online quizzes, exams, or homework as a group; getting answers for online quizzes, exams, or homework from the internet or textbooks; and using un-prescribed Adderall to help with studying.

Participants were asked to self-report their engagement in any of the proposed cheating behaviors. Each question used a 4-point scale (never, once, 2-5 times, and more than 5 times) to determine how frequently the participant had engaged in that form of cheating. The Cronbach's alpha for the cheating frequency scale was 0.88 .

Justification. Students were asked the same questions as in the cheating behavior section; however, they were now asked whether they considered this behavior to be a form of cheating. Questions used a 3-point scale that included definitely cheating (-1), unsure (0), and definitely not cheating (1). The Cronbach's alpha for the justification of cheating behaviors scale was 0.91 ; higher scores indicated greater justification of behaviors as not cheating.

Personal Values. The Variable Length Values Inventory (VLVI; Parks-Leduc et al., 2018) was used to measure personal values. The VLVI includes 26 items from all values 


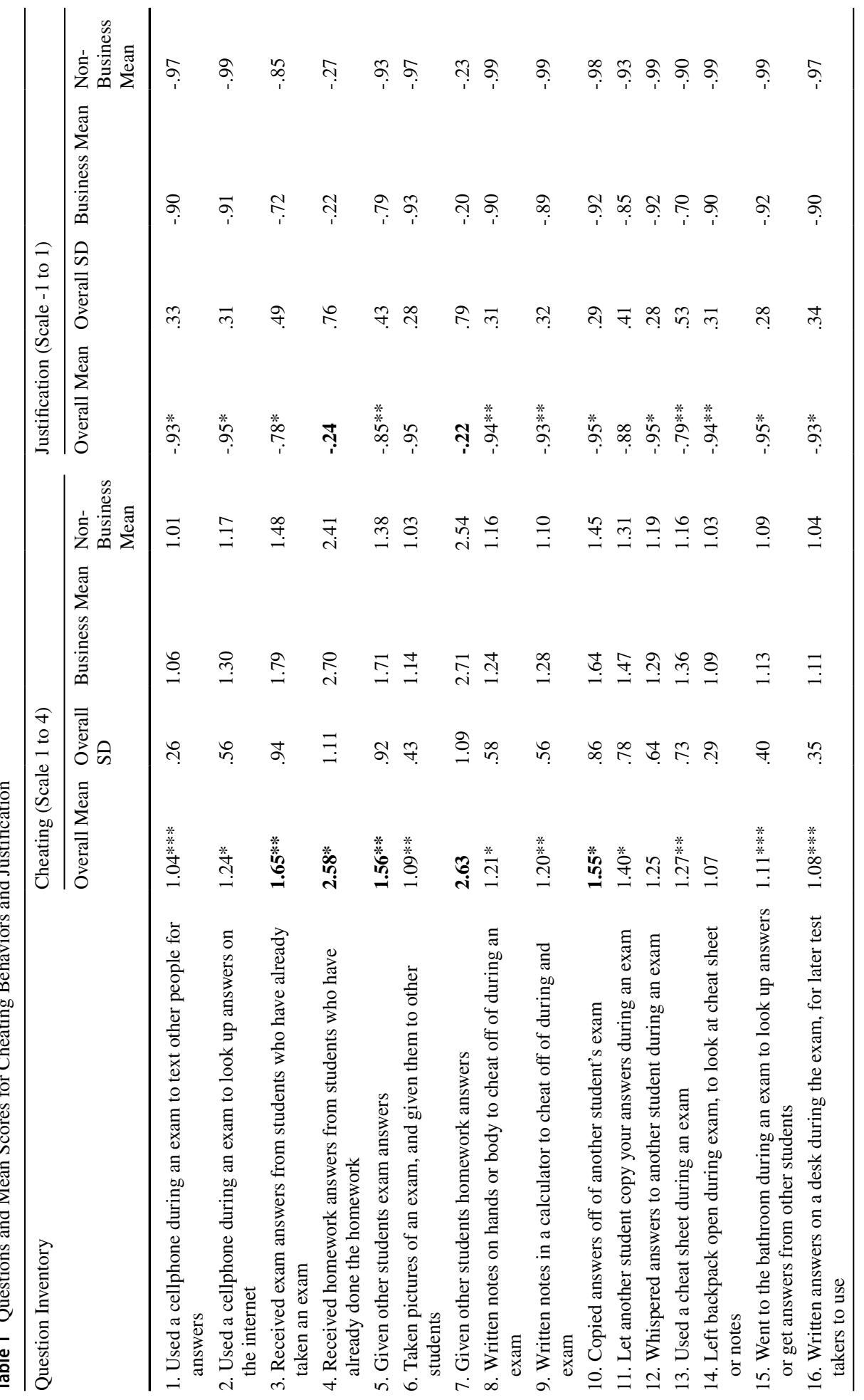




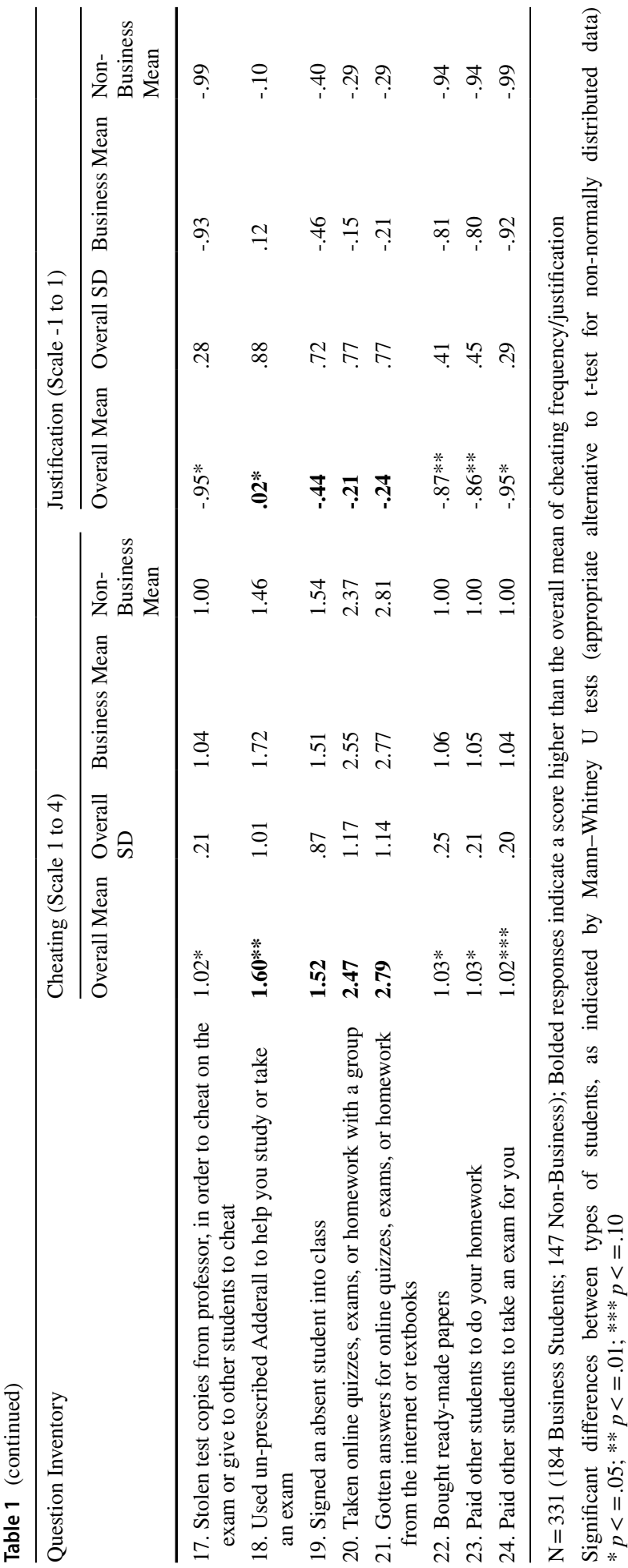


domains, which is used to calculate a mean value score, consistent with theory and research pertaining to values (see, for example, Parks-Leduc et al., 2015; Schwartz, 1992). As is common practice, the mean value score was used as a covariate in our analyses in order to control for scale response bias. This is done because within individuals, what drives behavior is how important one value is relative to other values (see Parks-Leduc et al., 2015; Schwartz, 1992). With the VLVI, researchers can add additional items for the value domains of interest to ensure reliable subscales; power values were assessed with 6 items, including: obtaining status, wealth, and social power. Participants were asked to assess the importance of particular values as "a guiding principle in their life," with responses on a 9-point scale ranging from "opposed to my values" to "of supreme importance." The Cronbach's alpha for power was 0.86 . The reliability for the mean value score was 0.90 .

Gender. Gender was included as a control variable in our study model as some studies have found relationships between gender and ethical decision-making (Ghanem \& Mozahem, 2019; Ruegger \& King, 1992). To ensure students' anonymity, no other demographic data were collected.

\section{Analysis}

The survey data were recorded through Qualtrics and analyzed using SPSS. Table 1 provides the mean scores for each of the cheating behavior questions to show which particular cheating behaviors and cheating justifications were most prevalent. Overall scores for all students are provided, as well as comparisons of business vs. non-business students. The cheating behaviors with a greater mean than the overall cheating mean (1.48) are marked in bold in the table, which provides insights into the current trends and popularity of various cheating behaviors. The justification behaviors with a greater mean than the average $(-0.73)$ are similarly identified in Table 1 . Cheating behaviors with particularly high scores for cheating frequency included getting answers for online quizzes, exams, or homework from the internet or textbooks (2.79); giving other students answers to homework (2.63); receiving homework answers from other students (2.59); and taking individual online quizzes, exams, or homework within a group (2.48). These also tended to have high justification scores. Only about $10 \%$ of the participants reported never engaging in any of the listed cheating behaviors. Means, standard deviations, and inter-correlations for study variables are provided in Table 2.

\section{Results}

Our hypotheses were tested using Structural Equation Modelling with AMOS in SPSS. However, we first examined differences between business and non-business students using independent samples t-tests. Business students were significantly more likely to be male, as males represented $57 \%$ of business students in the sample compared to $29 \%$ of nonbusiness students $(t(330)=5.34, p<0.01)$. As will be discussed in detail when examining the specific hypotheses, business students were more likely to cheat and to justify their cheating behaviors relative to non-business students, and they scored significantly higher on power values relative to non-business students.

For path analyses, gender was included as a control variable, and the mean value score was included as a covariate of power values, as is typical with values research (ParksLeduc et al., 2015; Schwartz, 1992). Our predicted model (Model 1) included paths for all 


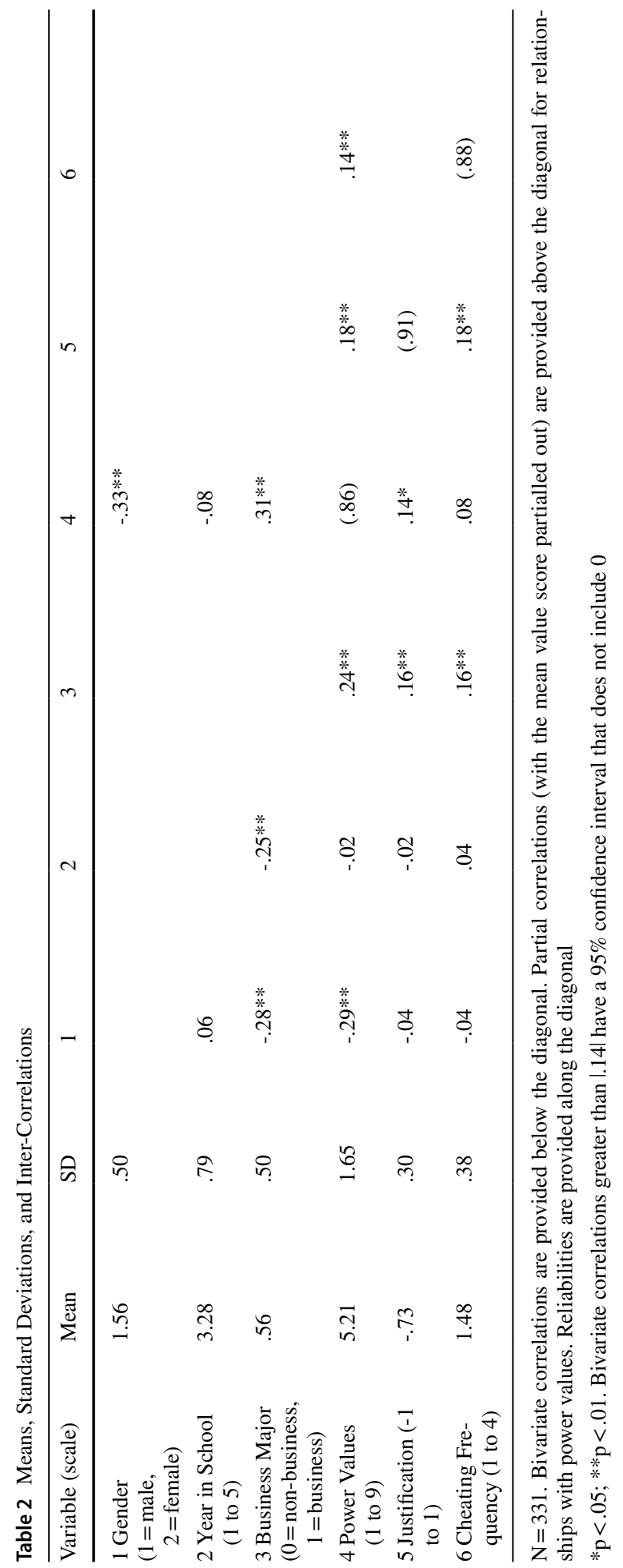




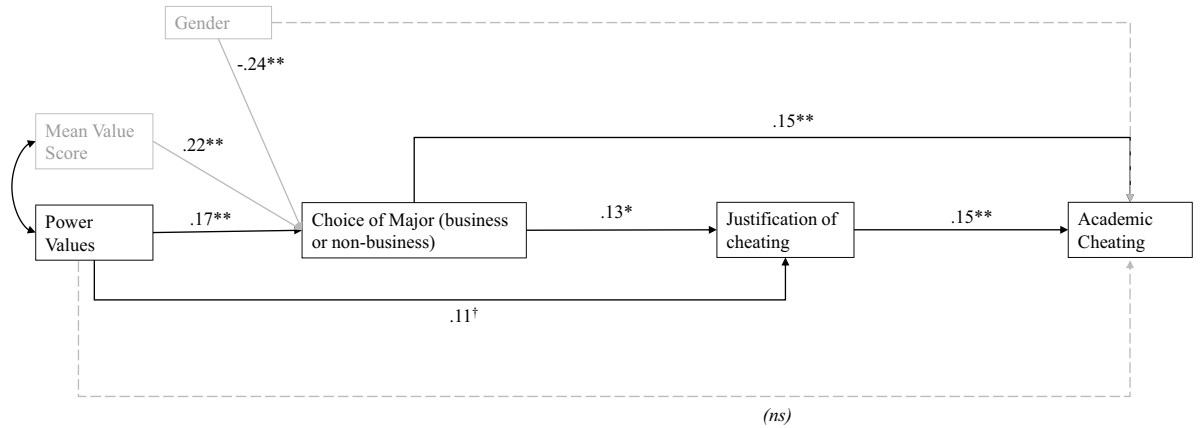

Fig. 2 Actual Path Model

hypotheses. Model fit was assessed using the Goodness of Fit Index (GFI), Comparative Fit Index (CFI), and Root Mean Squared Error of Approximation (RMSEA); scores above 0.90 indicate acceptable fit for the GFI and CFI, while scores below 0.06 indicate good fit for the RMSEA (Hooper et al., 2008). Fit indices for Model 1 were: $\mathrm{GFI}=0.98$; $\mathrm{CFI}=0.94$; and RMSEA $=0.10$. Because the RMSEA was higher than desired, we also examined modification indices for the model. These suggested that model fit could be improved by adding a path from the mean value score to choice of major. The addition of this path yielded fit indices for Model 2 as follows: $\mathrm{GFI}=0.99$; $\mathrm{CFI}=0.99$; $\mathrm{RMSEA}=0.05$. As this path was not predicted, we review path analyses from both models to provide support for our hypotheses. The full model (Model 2) is presented in Fig. 2. We also considered alternate models in which the order of mediation was reversed to test the robustness of our model; Model 3 had a path from choice of major to power values rather than the reverse, and Model 4 had paths from choice of major and justification to power values, rather than the reverse. Both yielded significantly worse fit statistics (for Model 3, GFI $=0.87, \mathrm{CFI}=0.25$, RMSEA =0.32; for Model 4, GFI=0.87, CFI=0.25, RMSEA =0.45).

Hypothesis 1 proposed that business students would report engaging in more cheating than non-business students. As noted previously, an independent samples t-test showed that business students had significantly higher mean scores $(\mathrm{M}=1.53, \mathrm{sd}=0.40)$ compared to non-business students $(\mathrm{M}=1.41, \mathrm{sd}=0.33), t(330)=-3.01, p<0.01$. Additionally, the standardized path estimate for this relationship was 0.13 in both Model 1 and Model 2 $(p=0.02)$. Hypothesis 1 was therefore supported. Hypothesis 2 examined justification as a predictor of cheating; the path estimate for this relationship was 0.15 in both models $(p<01)$. Hypothesis 2 was also supported; business students reported engaging in justification more than non-business students.

Hypothesis 3 stated that power values would be related to cheating. The partial correlation between power values and cheating after controlling for mean value score was 0.14 $(p<0.01)$. In our path model, the direct path from power values to cheating was not significant, however we tested the indirect effects using bootstrapping with 500 bootstrap samples and $95 \%$ bias-corrected confidence intervals. In Model 1, the standardized total effect of the direct and indirect paths was 0.07 (0.10 in Model 2). In both Models, the total effect fell within the bootstrapped confidence intervals (0.016-0.101 in Model 1; 0.025-0.128 in Model 2), demonstrating that the total effect of the relationship between power values and cheating was significant (0.07 in Model 1; 0.10 in Model 2; $p<0.01)$, partially supporting Hypothesis 3. 
Hypothesis 4a stated that business students would score higher on power values relative to non-business students. The standardized path estimate from power values to choice of major was $0.17(p<0.01)$ in Model 1, and $0.32(\mathrm{p}<0.01)$ in Model 2. The independent samples t-test showed that business students had significantly higher mean scores for power values $(\mathrm{M}=5.56, \mathrm{sd}=1.65$ for business students vs. $\mathrm{M}=4.77$, $\mathrm{sd}=1.54$ for non-business students; $t(330)=-4.45, p<0.01)$, in support of Hypothesis $4 \mathrm{a}$. Hypothesis $4 \mathrm{~b}$ stated that major (business or non-business) would mediate the relationship between power values and cheating. Significant path estimates from power values to choice of major, and from choice of major to cheating - as well as the significant indirect effect of power values on cheating - provide support for this hypothesis.

Hypotheses $5 \mathrm{a}$ and $5 \mathrm{~b}$ proposed that power values would be related to justification, and that justification would mediate the relationship between power values and cheating. The standardized path estimate from power values to justification was $0.11(p=0.05)$ in both Models, in support of Hypothesis 5a. As paths from power values to justification and from justification to cheating were significant, and the indirect effect of the relationship between power values and cheating was significant, Hypothesis $5 \mathrm{~b}$ was also supported.

Finally, Hypothesis 6 suggested that justification would mediate the relationship between choice of major and cheating. As with Hypothesis 3, we examined the bootstrapped results for this hypothesis. The standardized path estimate from choice of major to cheating was significant $(0.13 ; p=0.02)$ in both models. The total effect of choice of major on cheating was $0.15(p=0.02)$, and the indirect effect was significant. As the direct effect between choice of major and cheating was also significant, this suggests that justification partially mediates the relationship between choice of major and cheating, providing partial support for Hypothesis 6.

\section{Discussion}

Our goal with this study was to enhance our understanding of why and how students - especially business students - cheat. This study examined academic cheating behaviors and their relationships with personal values, justification, and college major. We find that power values are positively related to academic cheating behaviors. Further, that relationship is mediated by justification and choice of major. The current findings show that underlying values likely differ for business students vs. non-business students. We also find evidence that business students engage in more justification. This suggests that business school coursework may contribute to unethical behavior, as some have speculated (e.g., Miller, 1999). It is also possible that business schools simply have organizational climates that are more conducive to cheating (Jackson et al., 2002), such that peer groups influence this behavior. For example, if business students are already more likely to be able to justify behavior due to higher power values, then they are around other students who are also able to justify unethical behavior. Their ability to justify might be increased merely due to peer group rather than specific or implied teaching in their formal coursework. This is consistent with work by McCabe and Trevino (1995) about institutional culture as well as by Stone et al. (2009) regarding subjective norms. ${ }^{2}$

${ }^{2}$ We thank an anonymous reviewer for sharing this idea of including peer groups. 


\section{Theoretical Implications}

There is still much debate over the role that individuals and universities play in shaping how college students learn ethics. Our study examined the ethics of college students through the investigation of academic cheating behaviors and factors that influence those cheating behaviors. Consistent with past research (e.g., Bowers, 1967; McCabe \& Trevino, 1995), we found that business students admit to cheating more often than nonbusiness students. In addition, consistent with the theory of self-concept maintenance (Mazar et al., 2008), we found that students justify their behaviors as not cheating, and that justification is related to cheating. We also found that some types of cheating are easier to justify, and are therefore more prevalent. Additionally, while non-business students are also likely to justify their cheating behaviors, business students are more likely to do so, which adds to our understanding of how business and non-business students differ. Further, individual differences in values may influence these mechanisms, as power values are positively related to being a business major, to justification, and to cheating.

Our study also examines more contemporary methods of cheating. Two of the most frequent types of cheating were also the two that were most likely to be justified as not cheating; specifically, when taking quizzes or exams or completing homework assignments online, students often reported cheating on these assessments by either looking up the answers or by completing the assessments as part of a group. It seems possible that students cheat more often on online exams because it is often easier, thus something they can justify as okay. Online assessment may also represent a weaker situation with more ambiguous expectations, which may make cheating easier to justify. Professors who allow students to complete assessments online, or who have moved online because of the COVID-19 pandemic, should be aware that cheating is more prevalent when students complete work online.

We also contribute to the body of research on college cheating by considering the use of un-prescribed Adderall, a drug used to treat Attention Deficit and Hyperactivity Disorder, or ADHD, to enhance test performance. Adderall, a cognitive-enhancing drug (El Hazzouri et al., 2015), has been linked to greater alertness, motivation, and concentration (Wertheim, 2017). Since this is a relatively new phenomenon, there is little research on the prevalence of Adderall as a test-taking tool. We did find one study that reported $34 \%$ of its college student sample using ADHD stimulants illegally as study aids (DeSantis et al., 2008). In our study, 30\% of participants reported having used unprescribed Adderall at least once to aid in studying, 22\% used it at least twice, and $8 \%$ more than 5 times. These are seemingly high numbers considering the rate of ADHD in the general adult population is $4.4 \%$ (Wertheim, 2017). In addition, students used Adderall more than other cheating techniques on average.

Although the use of Adderall is akin to the use of performance-enhancing drugs in sports, most students did not consider taking un-prescribed Adderall to be a form of cheating. While the mean score for justifications was -0.73 , the mean score for justification of un-prescribed Adderall use was 0.02. More students justified this as not cheating. This is a concern not only as an ethical issue but also as a growing health issue. The non-medical use of Adderall by adults increased $67.1 \%$ between 2006 and 2011 (Wertheim, 2017). A CNN article (Yanes, 2014) on the trend of Adderall use among college students discussed the problems this can cause, including but not limited to the potential negative long-term effects of abusing the drug, the lack 
of understanding students have of its side effects and interactions with other drugs, and the lack of consideration students have for the illegality of buying and consuming Adderall without a prescription (Yanes, 2014). Furthermore, recent findings (Weyandt et al., 2018) suggest that Adderall has minimal or even adverse effects on cognitive processes for non-ADHD college students, thus making it unlikely to actually increase academic performance.

\section{Practical Implications}

One significant issue for practice associated with our research is whether the unethical behaviors in which individuals engage in college carryover to their careers. Research has found that unethical behaviors of college students relate to subsequent workplace unethicality (Graves, 2008; Ma, 2013). Companies are regularly faced with ethical dilemmas that can seriously affect their organization's reputation and success. Our findings that business students justify more and cheat more should be of major concern for businesses because these students make up a significant portion of their hiring pool and are likely to be the future leaders of their organizations (Brown \& Mitchell, 2010).

Another significant issue for practice is the fact that, as noted previously, academic cheating enables students to receive credit for learning that has not actually occurred. Fully $25 \%$ of participants stated that they had obtained homework answers from classmates more than 5 times. Rates were equally high for giving classmates homework answers and for completing online quizzes, exams, and homework as a group. These students are circumventing the goals of the educational institution. A fluid question is what should be done about the issue of cheating among college students (Rosile, 2007)? Universities are increasingly feeling pressure to produce ethical business students; while some universities attempt to teach ethical reasoning and decision making to their students, the learning from and overall success of business ethics courses is debated (Abend, 2013; Ghanem \& Mozahem, 2019; Molnar \& Kletke, 2012). We note that the underlying values of business students do seem to be different from those of non-business students; while business classes might have some influence on students' values, it is likely that the students' values had a significant influence on their choice of major. This suggests that a single course may not be sufficient to generate change in business students' propensity toward cheating.

The theory of self-concept maintenance (Mazar et al., 2008) suggests a potentially powerful yet simple approach to discouraging cheating: explicitly and frequently communicating to students what constitutes ethically appropriate and inappropriate behavior. At the organizational level, universities should consider establishing honor codes, which have a positive impact on academic integrity (McCabe et al., 1999). Professors can also use ethical reasoning (Ames et al., 2017; Cronan et al., 2018) and priming techniques such as honor code statements (Bing et al., 2012; Geiger, 1922; McCabe, 1993; McCabe et al., 1996, 2002) on tests, homework, and syllabi to remind students of their expectations in terms of ethical behavior (e.g., Gino \& Ariely, 2012). To the extent that business schools want their students to behave ethically despite constant pressure to excel in school in order to get a good-paying job or get admitted to graduate school (Burnett et al., 2016), professors need to raise students' understanding of and attention to what is ethical and thus help them to avoid justifications of cheating. 


\section{Limitations and Future Research}

Although this study possesses several strengths, there are limitations. Our data were collected from students at only one university, potentially limiting generalizability as values and education could vary across school or region; however, we do not feel that the students at the participating university differ significantly from students at other universities. Further, research has shown that cheating is a problem in Europe (Fox \& Meijer, 2008; Hendy et al., 2021) and Asia (Koul et al., 2009; Tsui \& Ngo, 2016) as well. Additionally, data were collected in a cross-sectional manner to help ensure confidentiality. As such, although our model is grounded in theory and prior empirical research, the survey design used in this study did not allow us to test causal relationships. Though we do show that values are related to being a business major, we cannot say definitively whether values influenced choice of major, or vice versa. Future research, using controlled experiments and/or longitudinal designs, could help clarify questions regarding causality. Nevertheless, Spector (2019; p.125) has recently demonstrated that:

The ability of the longitudinal design to reflect causality has been overstated and offers limited advantages over the cross-sectional design ... cross-sectional designs can provide evidence for relationships among variables and can be used to rule out many potential alternative explanations for those relationships.

Cross-sectional study designs continue to be the most popular design for most topics studied in organizational research that utilize survey methodology (Spector, 2019). Spector also states (p. 136) that "Longitudinal designs are not up to the challenge of addressing mediation, let alone more complex causal connections." In addition, a recent longitudinal study (Arieli et al., 2016) found little evidence of significant value change among business students over time. Still, we encourage future research in this area - using controlled experiments and/or longitudinal designs - to examine causality more definitively.

With students providing all self-report data at a single point in time, there is also the possibility of results being inflated by common source bias (Podsakoff et al., 2003). However, we used different scale anchors and a different number of scale points for each construct to reduce the likelihood of scale response bias. It is also possible that socially desirable responding was an issue; Fox and Meijer (2008) note that respondents often report dishonestly when asked sensitive questions such as those about their own academic dishonesty. We did ensure anonymity to reduce the likelihood of socially desirable responding, and the fact that most participants admitted to engaging in cheating suggests that this was effective. Future researchers, however, may want to use the randomized response technique recommended by Fox and Meijer (2008). Likewise, asking about cheating behaviors and justifications in the same survey may have created a demand effect that increased the observed relationship between the two measures. Future research using a longitudinal design will be needed to confirm this relationship. An additional limitation is that the development of our cheating (and justification) scale was not validated in a separate population prior to its inclusion here. The use of students to assist in developing the items, however, yielded interesting results, as we likely would not have included some behaviors, such as un-prescribed Adderall use, without input from students. As a result, our scale includes newer forms of cheating which had not been included in prior cheating scales. Finally, we note that our overall effects were not large. There are likely other predictors - whether related to the individual or the learning environment - that could also influence academic cheating behaviors. 
Future research from multiple universities and graduate student populations are needed to address the generalizability of our findings. In addition, a longitudinal study could offer insight into how students' behaviors, values, and morals fluctuate and change after being exposed to business and/or ethics classes. We encourage future research that examines the personal values and cheating behaviors of college students over their college careers. Qualitative interviews with students could further address the question of why students cheat. Given that values are relatively stable (Schwartz, 1992), these interviews could potentially offer more situational factors, as well as personal stories of how students' attitudes may change regarding what constitutes unethical behavior. Perhaps some students simply feel they deserve to pass and cheating is how they make that happen. Alternatively, it could be that social/organizational factors such as increased anonymity as a student are at play.

In summary, this study broadens our understanding of why and how business and nonbusiness students cheat by examining several possible antecedents to cheating and by considering a wide range of cheating behaviors that are relevant to contemporary students. We hope that this study will inform professors interested in reducing academic cheating. We also hope this study will stimulate future research on potential antecedents of cheating so that we can better understand how to resolve the cheating issue and help students to learn to behave ethically in school and in their future careers.

Funding This research was supported by funding from the Madison Collaborative and the College of Business of James Madison University.

Data Availability The dataset generated by this study is saved in the Mendeley data repository; DOI: $10.17632 / \mathrm{zt} 3 \mathrm{k} 6 \mathrm{jd} 9 \mathrm{z} 7.1$

\section{References}

Abend, G. (2013). The origins of business ethics in American universities, 1902-1936. Business Ethics Quarterly, 23, 171-205.

Ames, A., Smith, K. L., Sanchez, E. R. H., Pyle, L., Ball, T., \& Hawk, W. J. (2017). Impact and persistence of ethical reasoning education on student learning: Results from a module-based ethical reasoning education program. International Journal of Ethics Education, 2, 77-96.

Arieli, S., Sagiv, L., \& Cohen-Shalem, E. (2016). Values in business schools: The role of self-selection and socialization. Academy of Management Learning \& Education, 15(3), 493-507.

Ariely, D. (2009). Predictably irrational. Harper-Collins Publishers.

Ariely, D. (2013). The honest truth about dishonesty. Harper Perennial.

Barkan, R., Ayal., S., \& Ariely, D. (2015). Ethical dissonance, justifications, and moral behavior. Current Opinion in Psychology, 6, 157-161.

Bilsky, W., \& Schwartz, S. H. (1994). Values and personality. European Journal of Personality, 8, $163-181$.

Bing, M. N., Davison, H. K., Vitell, S. J., Ammeter, A. P., Garner, B. L., \& Novicevic, M. M. (2012). An experimental investigation of an interactive model of academic cheating among business school students. Academy of Management Learning \& Education, 11, 28-48.

Bowers, W. J. (1967). Student dishonesty and its control in college (Doctoral Dissertation, Columbia University). Retrieved from https://www.proquest.com/docview/302212913

Brown, M. E., \& Mitchell, M. S. (2010). Ethical and unethical leadership: Exploring new avenues for future research. Business Ethics Quarterly, 20, 583-616.

Burnett, A. J., Smith, T. M. E., \& Wessel, M. T. (2016). Use of the social cognitive theory to frame university students' perceptions of cheating. Journal of Academic Ethics, 14, 49-69.

Bye, H. H., Sandal, G. M., van de Vijfer, F. J. R., Sam, D. L., Cakar, N. D., \& Franke, G. H. (2011). Personal values and intended self-presentation during job interviews: A cross-cultural comparison. Applied Psychology: An International Review, 60, 160-182. 
Campbell, C. R., Swift, C. O., \& Denton, L. T. (2000). Cheating goes hi-tech: Online term paper mills. Journal of Management Education, 24, 726-740.

Chronicle of Higher Education. (2018). Building academic integrity: How one college promotes honesty in the classroom. http://results.chronicle.com/aicstii18?CHENLTIIBAIS1? elqTrack=true Accessed 28 October (2019).

Cronan, T. P., Mullins, J. K., \& Douglas, D. E. (2018). Further understanding factors that explain freshman business students' academic integrity intention and behavior: Plagiarism and sharing homework. Journal of Business Ethics, 147, 197-220.

Dean, K. L., \& Beggs, J. M. (2006). University professors and teaching ethics: Conceptualizations and expectations. Journal of Management Education, 30, 15-44.

DeSantis, A. D., Webb, E. M., \& Noar, S. M. (2008). Illicit use of prescription ADHD medications on a college campus a multimethodological approach. Journal of American College Health, 57, 315-324.

Drake, C. A. (1941). Why students cheat. Journal of Higher Education, 12, 418-420.

El Hazzouri, M., Carvalho, S. W., \& Main, K. J. (2015). An investigation of the emotional outcomes of business students' cheating "Biological Laws" to achieve academic excellence. Academy of Management Learning \& Education, 14, 440-460.

Faul, F., Erdfelder, E., Buchner, A., \& Lang, A.-G. (2009). Statistical power analyses using G*Power 3.1: Tests for correlation and regression analyses. Behavior Research Methods, 41, 1149-1160.

Feldman, G., Chao, M. M., Farh, J. L., \& Bardi, A. (2015). The motivation and inhibition of breaking the rules: Personal values structures predict unethicality. Journal of Research in Personality, 59, 69-80.

Festinger, L. (1957). A theory of cognitive dissonance. Stanford University Press.

Fox, J. P., \& Meijer, R. R. (2008). Using item response theory to obtain individual information from randomized response data: An application using cheating data. Applied Psychological Measurement, 32, $595-610$.

Frank, B., \& Schultz, G. (2000). Does economics make citizens corrupt? Journal of Economic Behavior \& Organization, 43, 101-113.

Geiger, J. R. (1922). The honor system in colleges. International Journal of Ethics, 32, 398-409.

Gert, J. (2014). Begging the question: A qualified defense. Journal of Ethics, 18, 279-297.

Ghanem, C. M., \& Mozahem, N. A. (2019). A study of cheating beliefs, engagement, and perception - The case of business and engineering students. Journal of Academic Ethics, 17, 291-312.

Giacalone, R. A., \& Wargo, D. T. (2009). The roots of the global financial crisis are in our business schools. Journal of Business Ethics Education, 6, 147-168.

Gino, F., \& Ariely, D. (2012). The dark side of creativity: Original thinkers can be more dishonest. Journal of Personality and Social Psychology, 102, 445-459.

Graham, M. A. (1994). Cheating at small colleges: An examination of student and faculty attitudes and behaviors. Journal of College Student Development, 35, 255-260.

Graves, S. M. (2008). Student cheating habits: A predictor of workplace deviance. Journal of Diversity Management, 3(1), 15-22.

Hawkins, D. I., \& Cocanougher, A. B. (1972). Student evaluations of the ethics of marketing practices: The role of marketing education. Journal of Marketing, 36, 61-64.

Hendy, N. T., Montargot, N., \& Papadimitriou, A. (2021). Cultural differences in academic dishonesty: A social learning perspective. Journal of Academic Ethics, 19, 49-70.

Hooper, D., Coughlin, J. \& Mullen, M. R. (2008). Structural equation modelling: Guidelines for determining model fit. The Electronic Journal of Business Research Methods, 6, 53-60. Retrieved from: https:// academic-publishing.org/index.php/ejbrm/article/view/1224

Huhn, M. P. (2014). You reap what you sow: How MBA programs undermine ethics. Journal of Business Ethics, 121, 527-541.

Ilies, J. J., \& Reiter-Palmon, R. (2008). Responding destructively in leadership situations: The role of personal values and problem construction. Journal of Business Ethics, 82, 251-272.

Jackson, C. J., Levine, S. Z., Furnham, A., \& Burr, N. (2002). Predictors of cheating behavior at a university: A lesson from the psychology of work. Journal of Applied Social Psychology, 32, 1031-1046.

Jendrek, M. P. (1992). Students' reactions to academic dishonesty. Journal of College Student Development, 33, 260-273.

Jensen, L. A., Arnett, J. J., Feldman, S. S., \& Cauffman, E. (2002). It's wrong, but everybody does it: Academic dishonesty among high school and college students. Contemporary Educational Psychology, 27, 209-228.

Klein, H. A., Levenburg, N. M., McKendall, M., \& Mothersell, W. (2007). Cheating during the college years: How do business students compare? Journal of Business Ethics, 72, 197-206.

Koul, R., Clariana, R. B., Jitgarun, K., \& Songsriwittaya, A. (2009). The influence of achievement goal orientation on plagiarism. Learning and Individual Differences, 19, 506-512. 
Krishnan, V. R. (2008). Impact of MBA education on students' values: Two longitudinal studies. Journal of Business Ethics, 83, 233-246.

Lan, G., Gowing, M., McMahon, S., Rieger, F., \& King, N. (2008). A study of the relationship between personal values and moral reasoning of undergraduate business students. Journal of Business Ethics, 78, 121-139.

Lee, J. J., Ong, M., Parmar, B., \& Amit, E. (2019). Lay theories of effortful honesty: Does the honesty-effort association justify making a dishonest decision? Journal of Applied Psychology, 104(5), $659-677$.

Ma, Z. (2013). Business students' cheating in classroom and their propensity to cheat in the real world: A study of ethicality and practicality in China. Asian Journal of Business Ethics, 2(1), 65-78.

Mangan, K. (2006). Survey finds widespread cheating in MBA programs. Chronicle of Higher Education, 53(6), 44.

Mazar, N., Amir, O., \& Ariely, D. (2008). The dishonesty of honest people: A theory of self-concept maintenance. Journal of Marketing Research, 45, 633-644. https://doi.org/10.1509/jmkr.45.6.633

McCabe, D. L. (1993). Faculty responses to academic dishonesty: The influence of student honor codes. Research in Higher Education, 34, 647-658.

McCabe, D. L., Dukerich, J. M., \& Dutton, J. (1993). Values and moral dilemmas: A cross-cultural comparison. Business Ethics Quarterly, 3, 117-130.

McCabe, D. L., \& Trevino, L. K. (1995). Cheating among business students: A challenge for business leaders and educators. Journal of Management Education, 19(2), 205-218.

McCabe, D. L., Trevino, L. K., \& Butterfield, K. D. (1996). The influence of collegiate and corporate codes of conduct on ethics-related behavior in the workplace. Business Ethics Quarterly, 6, 461-476.

McCabe, D. L., Trevino, L. K., \& Butterfield, K. D. (1999). Academic integrity in honor code and nonhonor code environments: A qualitative investigation. The Journal of Higher Education, 70, 211234. https://doi.org/10.1080/00221546.1999.11780762

McCabe, D. L., Trevino, L. K., \& Butterfield, K. D. (2002). Honor codes and other contextual influences on academic dishonesty: A replication and extension to modified honor code settings. Research in Higher Education, 43, 357-378.

Miller, D. T. (1999). The norm of self-interest. American Psychologist, 54, 1053-1060.

Molnar, K. K., \& Kletke, M. G. (2012). Does the type of cheating influence undergraduate students' perceptions of cheating? Journal of Academic Ethics, 10, 201-212.

Owusu, G. M. Y., Bekoe, R. A., Koomson, T. A. A., \& Simpson, S. N. Y. (2019). Temptation and the propensity to engage in unethical behaviour. International Journal of Ethics and Systems, 35, 43-58.

Parks, L., \& Guay, R. P. (2009). Personality, values, and motivation. Personality and Individual Differences, 47, 675-684.

Parks, L., \& Guay, R. P. (2012). Can personal values predict performance? Evidence in an academic setting. Applied Psychology: An International Review, 61(1), 149-173.

Parks-Leduc, L., Feldman, G., \& Bardi, A. (2015). Personality traits and personal values: A meta-analysis. Personality and Social Psychology Review, 19, 3-29.

Parks-Leduc, L., Parks, T.W., \& Wang, G. (2018). The variable length values inventory. Paper presented at the Annual Conference of the Southern Management Association (SMA), Lexington, KY.

Pedersen, T. (2018). Rationalization. Psych Central. Retrieved on May 29, 2018, from https://psychcentral. com/encyclopedia/rationalization/

Podsakoff, P. M., MacKenzie, S. B., Lee, J. Y., \& Podsakoff, N. P. (2003). Common method biases in behavioral research: A critical review of the literature and recommended remedies. Journal of Applied Psychology, 88, 879-903.

Pohling, R., Bzdok, D., Eigenstetter, M., Stumpf, S., \& Strobel, A. (2015). What is ethical competence? The role of empathy, personal values, and the five-factor model of personality in ethical decisionmaking. Journal of Business Ethics, 137, 449-474.

Rokeach, M. (1973). The nature of human values. The Free Press.

Rosile, G.A. (2007). Cheating: Making it a teachable moment. Journal of Management Education, 31, 582-613.

Ruegger, D., \& King, E. W. (1992). A study of the effect of age and gender upon student business ethics. Journal of Business Ethics, 11, 179-186.

Sagiv, L., \& Schwartz, S. H. (2000). Value priorities and subjective well-being: Direct relations and congruity effects. European Journal of Social Psychology, 30(2), 177-198.

Schwartz, S. H. (1992). Universals in the content and structure of values: Theoretical advances and empirical tests in 20 countries. In M. P. Zanna (Ed.), Advances in experimental social psychology (pp. 1-65). Academic Press. 
Schwartz, S. H. (2011). Values: Individual and cultural. In F. J. R. van de Vijver, A. Chasiotis, \& S. M. Breugelmans (Eds.), Fundamental questions in cross-cultural psychology (pp. 463-493). Cambridge University Press.

Shalvi, S., Eldar, O., \& Bereby-Meyer, Y. (2012). Honesty requires time (and lack of justifications). Psychological Science, 23, 1264-1270.

Sheldon, K. M., \& Elliott, A. K. J. (1999). Goal striving, need satisfaction, and longitudinal well-being: The self-concordance model. Journal of Personality and Social Psychology, 76, 482-497.

Spector, P. E. (2019). Do not cross me: Optimizing the use of cross-sectional designs. Journal of Business and Psychology, 34, 125-137.

Stone, T. H., Jawahar, I. M., \& Kisamore, J. L. (2009). Using the theory of planned behavior and cheating justifications to predict academic misconduct. Career Development International, 14(3), 221-241.

Tsui, A. P. Y., \& Ngo, H. Y. (2016). Social predictors of business student cheating behaviour in Chinese societies. Journal of Academic Ethics, 14, 281-296.

Wang, L., Malhotra, D., \& Murnighan, J. K. (2011). Economics education and greed. Academy of Management Learning \& Education, 10, 643-660.

Wenzel, K., \& Reinhard, M. (2020). Tests and academic cheating: Do learning tasks influence cheating by way of negative evaluations? Social Psychology of Education, 23, 721-753.

Wertheim, L. J. (2017). Attention deficit. Sports Illustrated, 27(17), 58-63. Retreived from: https://vault.si. com/vault/2017/12/04/attention-deficit

West, T., Ravenscroft, S., \& Shrader, C. B. (2004). Cheating and moral judgment in the college classroom: A natural experiment. Journal of Business Ethics, 54, 173-183.

Weyandt, L. L., White, T. L., Gudmundsdottir, B. G., Nitenson, A. Z., Rathkey, E. S., De Leon, K. A., \& Bjorn, S. A. (2018). Neurocognitive, autonomic, and mood effect of Adderall: A pilot study of healthy college students. Pharmacy, 6, E58.

Whitley, B. E. (1998). Factors associated with cheating among college students: A review. Research in Higher Education, 39(3), 235-274.

Yanes, A. (2014), April 18. Just say yes? The rise of 'study drugs' in college. Retrieved from: http://www. cnn.com/2014/04/17/health/adderall-college-students/

Publisher's Note Springer Nature remains neutral with regard to jurisdictional claims in published maps and institutional affiliations. 